\title{
Pengembangan UKM Online Bagi Para Pengrajin Kapal Kayu di Kelurahan Tanah Lemo, Kecamatan Bontoharu, Kabupaten Bulukumba
}

\author{
Hasnawiya $\operatorname{Hasan}^{1 *}$, Andi Haris Muhammad ${ }^{1}$, Rahimuddin $^{1}$,A.Husni Sitepu ${ }^{1}, Z u l k i f l i{ }^{1}$, \\ Baharuddin $^{1}$, Agung Setiawan ${ }^{1}$, Sabaruddin ${ }^{2}$ \\ Departemen Teknik Sistem Perkapalan, Fakultas Teknik Universitas Hasanuddin ${ }^{1}$ \\ Departemen Teknik Kelautan Fakultas Teknik Universitas Hasanuddin ${ }^{2}$ \\ hasnarazak07@gmail.com ${ }^{1 *}$
}

\begin{abstract}
Abstrak
Masyarakat di Kelurahan Tanah Lemo, Kecamatan. Bontoharu, Kabupaten Bulukumba, merupakan pengrajin kapal phinisi yang telah menjual selama puluhan tahun. Namun, kapal ini tidak sukses dipasarkan olehkarena sistem pemasaranya tradisional. Seringkali para pengrajin membutuhkan bantuan pihak ketiga untuk mendapatkan pembeli. Sehingga keuntungan yang mereka dapatkan tidak tinggi, padahal pembuatan kapal ini berat dan lama.

Namun, phinisi merupakan aset yang mampu diekspor, karena adanya pengakuan UNESCO mengenai phinisi sebagai karya seni yang indah.

Prosedur yang digunakan dalam melaksanakan pengabdian ini, terbagi atas beberapa subyek, antara lain :

- pengambilan data dan analisa data. Pengambilan data dilakukan dengan mengadakan wawancara dengan pengrajin dan observasi proses pembuatan phinisi.

- desain website, dan peluncuran website. .

Output dari subyek ini berupa :

- proses pembuatan phinisi, .

- kendala dalam usaha phinisi.

- potensi kerajinan phinisi dalam menciptakan lapangan kerja dan kesejahteraan.

Kemudian tim pengabdian melakukan analisa atas data tersebut, yang hasilnya antara lain:

- menentukan tujuan pembuatan website yaitu menjadi jembatan bagi produsen dan konsumen

- merangkum beberapa hal penting yang perlu digambarkan dalam website ini.

Hasil analisa tersebut menjadi acuan dalam menyusun format website. Format website dari kerajinan phinisi ini, antara lain :

- menggambarkan phinisi bukan hanya sebagai sebuah karya seni tapi juga memilki ketangguhan berlayar hingga keliling dunia.

- website ini perlu menggambarkan kredibilitas UKM ini, yang sering menjual phinisi hingga

Mancanegara.

Kemudian, berdasarkan format tersebut, pembuatan website dilakukan dengan teknik hand coding agar fleksibel dan mudah dimodifikasi. Capaian yang diharapkan dalam pengabdian ini adalah, memperkenalkan Phinisi di mancanegara dan memasarkankannya. Sehingga secara tidak langsung berdampak pada peningkatan kesejahteraan masyarakat lokal dan membuka lowongan pekerjaan baru.

Kesimpulannya, karena tingginya minat masyarakat terhadap Phinisi, maka pemutakhiran pemasaran dilakukan dengan perancangan websites. Website diharapkan menjadi jembatan bagi usahawan phinisi dengan konsumennya di segala penjuru dunia.
\end{abstract}

Kata Kunci : Coding; Phinisi; Kapal ; UKM; Websites.

\section{Abstract}

People in Kelurahan Tanah Lemo, Kecamatan. Bontoharu, Kabupaten Bulukumba, is phinisi ship craftman which has sold phinisi for years. However, phinisi business is not sucsessfull due to its traditional marketing system. Often, these craftman needs help from the third party in order to find buyers. So, they do not get high profit, eventhough the build process is heavy.

However, this phinisi is potential to be exported, due to UNESCO acknowledgment about phinisi as a beautifull art creation.

Procedure that is used in this program, consist of:

- collecting and analysis data by interviewing the phinisi owner and observe the process of ship building. 
- website format design and develope.

The output of the subjects; consist of:

- process of ship building.

- obstacles in phinisi business.

- potency of phinisi business.

In addition, output of analysis those data, which are:

- define the aim of website which is to be the bridge for producer and consumer.

- summaries some important point that need to be shown in this website.

The analysis result become a reference in design the website which is consist of:

- showing phinisi as an art creation as well as its capability in sailing around the world.

- eventhough this website only for UKM, but still need to express its credibility.

Therefore, the website is build using hand coding technique so its flexible and easy to modify.

The target which is expected is introducing phinisi in overseas and increasing its marketing. So, this business impact on the increaseness of prosperity and a new vocation. In conclusion, due to the society high interest to phinisi, digitization of marketing system for phinisi is conducted using a website. This website is expected become a bridge for phinisi business and their buyers around the world.

Keywords: Coding; Phinisi; Ship; UKM; Websites.

\section{Pendahuluan}

\subsection{Analisis Situasi}

Desa Tanah Lemo yang terletak di Kabupaten Bulukumba, Sulawesi Selatan, memiliki pemandangan alam pantainya yang indah dan masih asri belum terjamah. Selain daripada itu, Desa Tanah Lemo juga terkenal mewarisi kebudayaan nenek moyang Sulawesi Selatan yaitu keterampilan membuat kapal kayu Phinisi yang telah diturunkan berabad-abad yang lalu.

Kapal kayu Phinisi dikenal sebagai kapal kayu yang sangat kuat dan mampu berlayar mengelilingi dunia sejak berabad-abad yang lalu, meski tidak dirancang sesuai dengan metode teknik perkapalan modern. Kerajinan phinisi merupakan salah satu mata pencaharian masyarakat di desa ini selain bertai dan nelayan. Namun, karena keadaan tanah desa yang kurang subur dan kurang majunya usaha phinisi membuat banyak penduduk desa yang merantau ke luar daerah seperti makassar ddan jakarta utuk mecari pekerjaan. Harapan mereka pada usaha phinisi makin lama makin surut olehkarena merosotnya penjualan phinisi dari tahun ke tahun. Padahal phinisi terkenal dengan keperkasaannya hingga ke mancaegara.

Hal ini terbukti di tahun 2017, dimana kapal Phinisi dipakai untuk berlayar dari pantai bira menuju Vancouver Kanada dan sampai ditujuan dengan selamat. Hingga pada akhirnya, kapal Phinisi mendapat pengakuan dari UNESCO sebagai warisan budaya dan karya seni terbaik di dunia pada sebuah even bergengsi di Korea tahun 2017. Oleh karena itu, kapal Phinisi ini berpotensi untuk dikembangkan sebagai produk ekspor

Selain daripada itu, nilai jual kapal kayu phinisi ini cukup tinggi mencapai milyaran rupiah untuk sebuah kapal kayu berukuran besar. Sehingga diharapkan, usaha ini mampu meningkatkan pendapatan masyarakat lokal di daerah ini.

Mitra yang bekerjasama dengan tim pengabdian Unhas adalah UD. Bina Pusaka, merupakan sebuah usaha kecil menengah yang bergerak di bidang pembuatan kapal kayu dan berlokasi di Kelurahan Tanah Lemo, Kecamatan Bontoharu, Kabupaten Bulukumba. Permasalahan yang dihadapi mitra adalah umumnya mengenai biaya produksi yang cukup besar dan kurangnya 
penerapan teknologi dalam pembuatan kapal kayu. Sehingga pembuatan kapal kayu yang mereka lakukan hanya mampu satu hingga dua kapal besar setahun.

Sementara masyarakat yang akan dibina merupakan masyarakat lokal di daerah Kelurahan Tanah Lemo ini.

\subsection{Permasalahan Mitra}

Potensi kapal kayu Phinisi untuk menjadi produk ekspor terhadang dengan berbagai macam permasalahan. Salah satunya adalah kekurangan sumber daya manusia dan pengelolaan pembuatan kapal kayu dengan cara tradisional tampa teknologi membuat mitra terhambat dalam memajukan usaha kerajinan kapal kayu.

Oleh karena itu, kapal kayu Phinisi berukuran besar hanya mampu dihasilakn dua buah saja dalam setahun. Produk yang paling sering laku adalah kapal kayu berukuran kecil.

Kapal kayu phinisi selama ini baru diminati oleh para penggemar kapal saja dan para wisatawan asing yang kebetulan berlibur ke Pantai Bira. Kapal Phinisi ini sering dipakai untuk berlayar oleh turis asing dari Pantai Bira menuju raja ampat. Kapal berukuran besar paling sering diminati oleh masyarakat manccanegara. Namun, para pengrajin phinisi kesulitan untuk menemukan pembeli dari luar negri. Olehkarena para pengrajin phinisi ini mengelola usaha mereka masih dengan model yang sangat tradisional, sehingga sulit bagi mereka untuk berkembang lebih baik.

Meskipun kapal Phinisi telah mendapatkan pengakuan dari UNESCO sebagai salah satu karya seni dunia.

\section{Keterkaitan Kondisi Kemajuan Pemasaran Kapal Phinisi dengan IT}

Di era teknologi informasi ini, sudah sepatutnya memperkenalkan bisnis menggunakan media internet. Media yang sering digunakan individu maupun perusahaan dalam memasarkan bisnisnya adalah media blog maupun vlog. Dalam hal ini, sebuah website bisnis sudah cukup representatif dalam memasarkan bisnis yang dimiliki. Oleh karena dengan memanfaatkan media websites ini, individu maupun co-operative mampu merencanakan biaya produksi dengan lebih baik dan lebih matang.(Karnanda, 2013).

Penggunaan websites juga mampu mengangkat kepercayaan dari individu maupun co-operative yang memakainya. Desain website bisnis yang informatif, menarik dan profesional mampu menarik pelanggan dari seluruh dunia. Selain daripada itu juga menggambarkan kredibilitas individu maupun co-operative yang memakai websites tersebut. Sehingga, bisnis yang dilegkapi website sering lebih menarik perhatian konsumen dibandingkan yang tidak memiliki website. Website sering dinilai sebagai lambang atau ciri kemajuan dari bisnis tersebut.

Oleh karena itu, bisnis yang menggunakan websites sering kali dianggap lebih profesional dibandingkan bisnis yang konvensional (Neoelerning, 2014).

Website ini akan dipakai sebagai sarana yang memperkenalkan kapal Phinisi sebagai kapal tradisional yang tangguh dan mampu berlayar keliling dunia serta karya seni budaya warisan nenek moyang masyarakat Sulawesi Selatan berabad-abad yang lalu.

Selain daripada itu, juga memperkenalkan pantai di Desa Tanah Lemo sebagai daerah wisata bahari yang masih asri kepada wisatawan nasional maupun manca negara. 
Pemanfaatan website bisnis ini akan memudahkan para usahawan kapal phinisi untuk berkembang dan memperkenalkan karya mereka hingga mancanegara.

\section{Metode Untuk Menangani Permasalahan}

Salah satu UKM di Kelurahan Tanah Lemo Kecamatan Bontoharu Kabupaten Bulukumba ini bergerak di bidang usaha kapal phinisi bernama UD. Bina Pusaka yang dipimpin oleh Bapak H. Abdullah. UD. Bina Pusaka telah lama menjual kapal Phinisi ke manca negara hingga ke Belanda, Jerman, Spanyol, Amerika, dan Itali. Namun, kekurangan UKM ini adalah sulitnya berhubungan langsung dengan pelanggan tanpa melalui perantara, sehingga menyebabkan UD.Bina Pusaka kurang berkembang. Olehkarena itu, tim pengabdian Unhas membuatkan sebuah websites bisnis untuk UKM ini, agar mereka dapat berhubungan langsung dengan pelanggan mereka vie website ini.

Websites bisnis ini dirancang dengan menggunakan metode hand coding. Website coding terbagi atas tiga bagian yaitu ;

a. Front end ; yaitu bagian dari websites yang bertanggung jawab terhadap isi dan tampilan dari website. Front end developer bertanggung jawab mengatur isi dari website, memperbaiki tampilan dari websites tersebut. Bahasa pemograman yang wajib dikuasai front end developer antara lain HTML, CSS, dan Java script

b. Back end ; yaitu bagian belakang layar dari websites yang tidak berhubungan langsung dengan user. Bahasa pemograman yang sering dipakai pada posisi ini, antara lain ; phyton, ruby, $\mathrm{PHP}$.

c. Full stack adalah bagian dari websites yang bekerja pada front end dan back end .

Ada beberapa bahasa pemograman web yang digunakan dalam merancang sebuah web antara lain :

a. HTML; adalah singkatan dari Hypertext Markup Language merupakan bahasa pemograman paling dasar dalam membuat sebuah websites, menampilkan semua informasi dalam websites dengan fromat hipertext yang masih sederhana dan ditulis dalam format ASCII. Olehkarena itu, pada dasarnya websites adalah sebuah plain text yang telah mengalami encoded oleh HTML sehingga terformat baik pada web browser. Sejauh ini tealah ada revisi ke 5 dari HTML yang disebut HTML 5. Developer dapat memasukkan video, gambar,musik, dll (Faithe Wempen, 2011).

b. CSS ; adalah singkatan dari Cascading Style Sheet merupakan aturan untuk mengatur beberapa komponen dari HTML agar lebih terstruktur dan menarik. Dengan menggunakan CSS juga tampilan dari websites menjadi lebih menarik, berwarna, dan interaktif. Developer dapat memasukkan video, gambar, dan musik ke dalam website dan menfromatnya menjadi tampilan yang menarik. (Tiffani, 2015)

c. Javascript merupakan bahasa peogrman yang akan membuat websites menjadi lebih menarik saat dikerjakan bersama dengan HTML. Dengan javascript, web developer dapat menambah fitur interaktif, seperti memberikan respon pada waktu pengguna mengklik tombol memebrikan efek, memberikan animasi, dll. Java script dapat membuat tampilan website menjadi semakin menarik dan profesional. (Terry,2010). 
d. Phyton adalah bahasa pemograman yang digunakan para websites developer, utamanya yang berada pada bagian backend developer. Phyton umumya digunakan sebagai bahasa skrip dan lebih sering digunakan untuk membuat dan mengembangkan software, serta mampu berjalan di berbagai sistem operasi. (Tim Hall and JP Stacey, 2009).

Beberapa tampilan dari website bisnis kapal Phinisi adalah sebagai berikut:

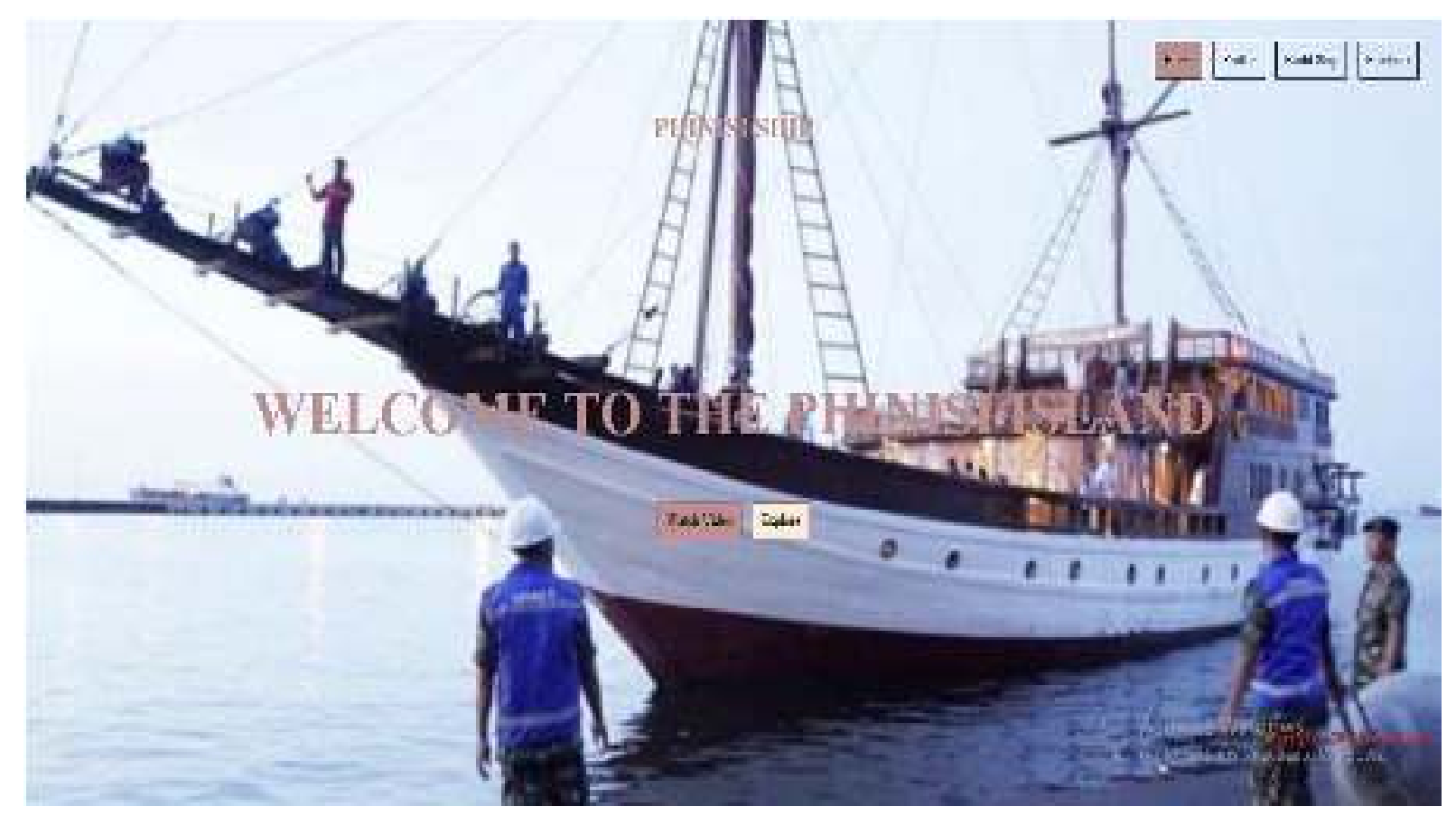

Gambar 1. Tampilan Awal dari Website Kapal Phinisi 


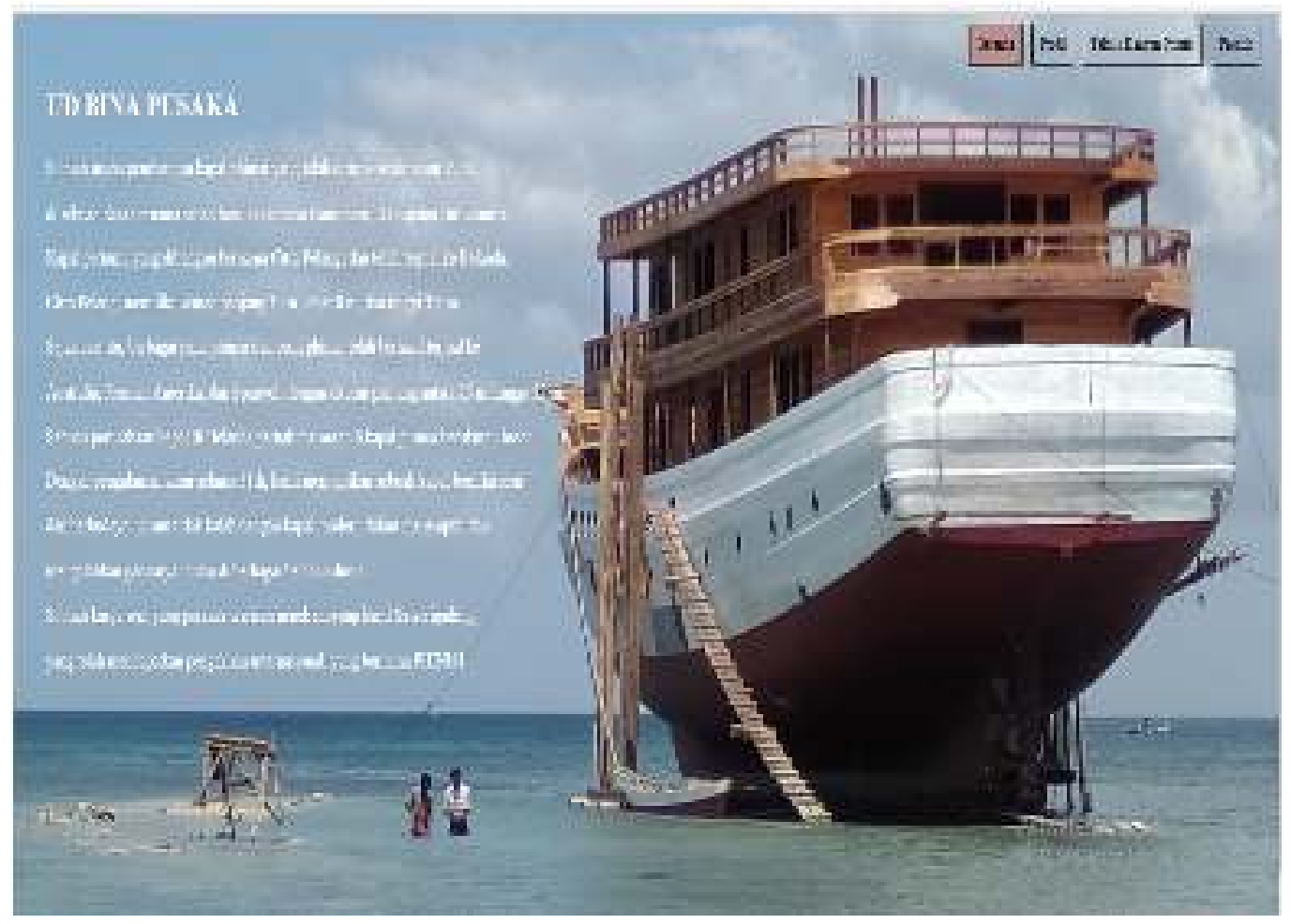

Gambar 2. Halaman Web yang Menjelaskan Profil UD. Bina Pusaka

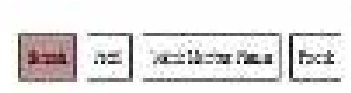

\section{UNDERCOXSTRLICTION PETTISI}

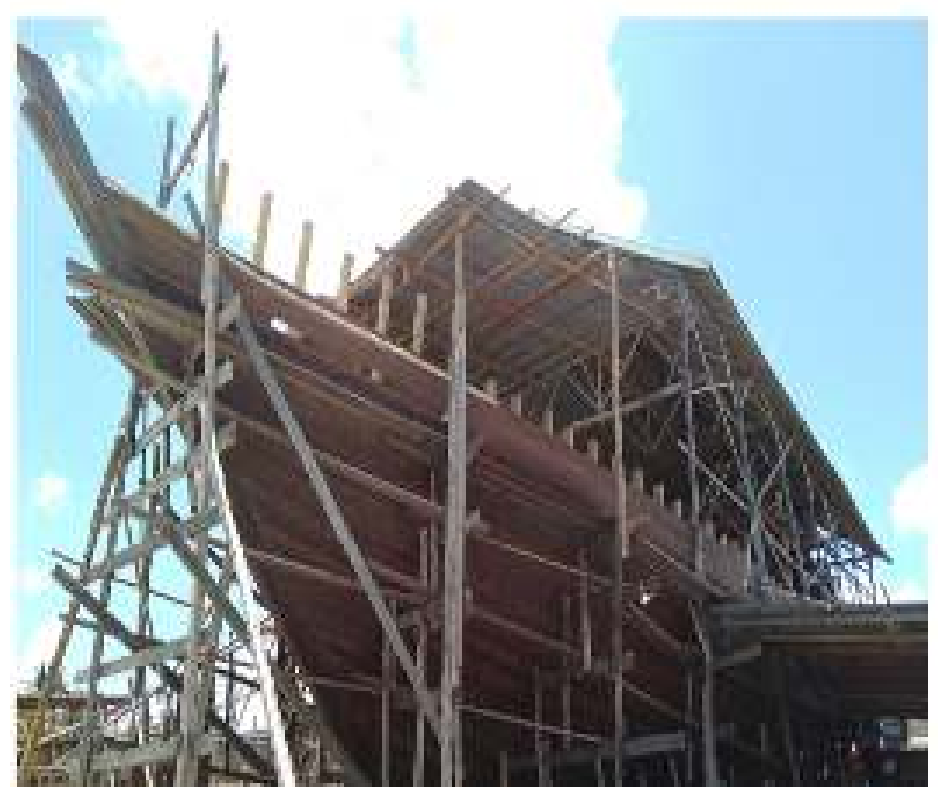

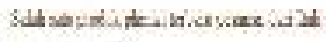

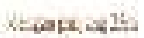

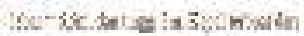

$$
\begin{aligned}
& \text { Distrodxcogon }
\end{aligned}
$$

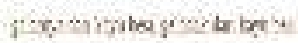

$$
\begin{aligned}
& \text { even onvies } \\
& \text { telar telosiph }
\end{aligned}
$$

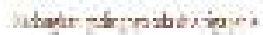

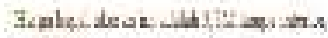

$$
\begin{aligned}
& \text { Leriadicienter }
\end{aligned}
$$

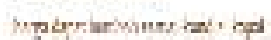

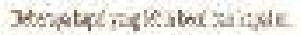

$$
\begin{aligned}
& \text { ober posale patupia: }
\end{aligned}
$$

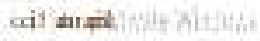

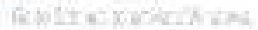

Gambar 3. Halaman Web yang Menggambarkan Kapal Phinisi yang Sementara Dibangun 


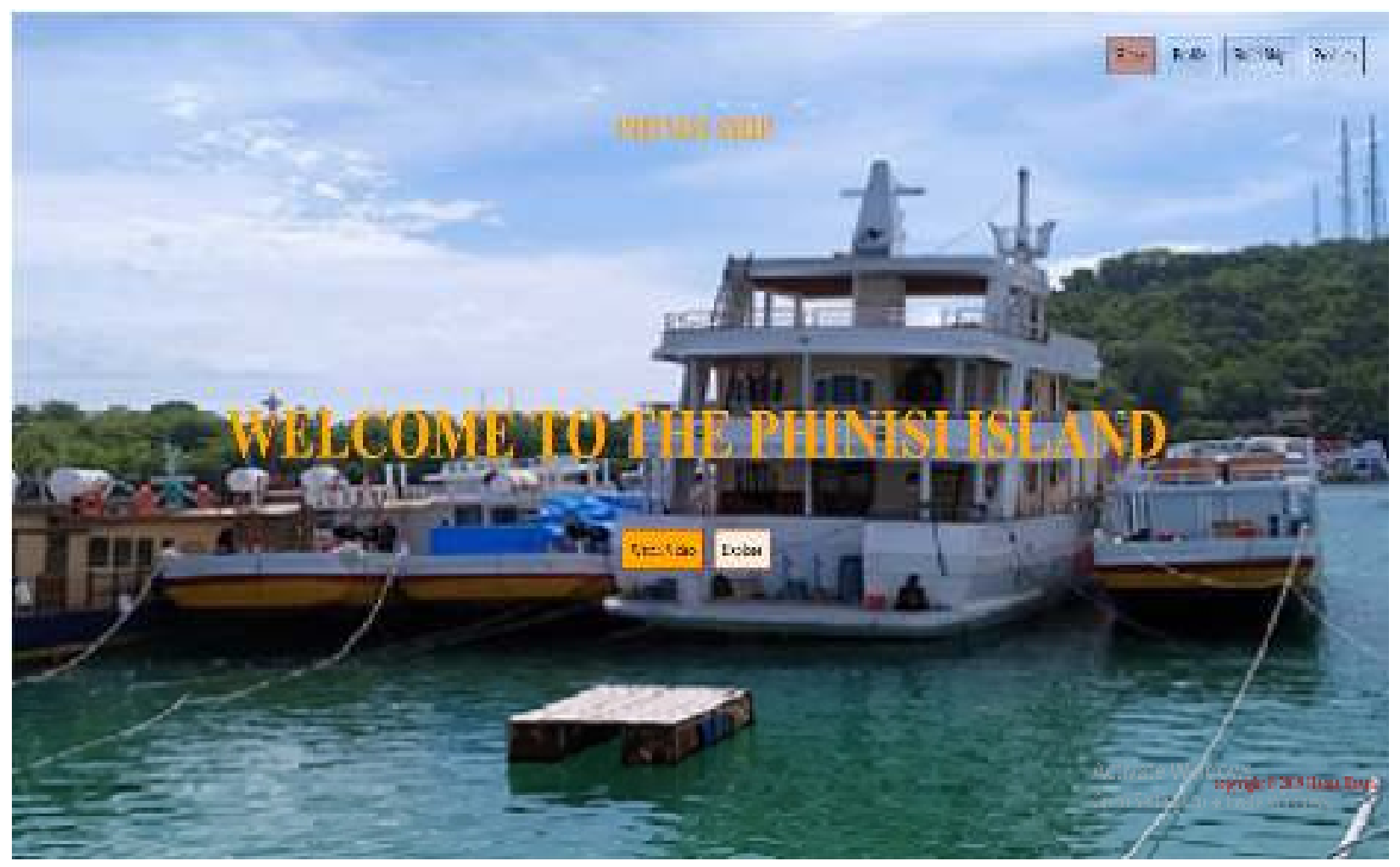

Gambar 4. Halaman Web yang Menjelaskan Proses Pembuatan Phinisi

Setiap halaman dari websites ini akan menjelaskan tentang profil UKM, sejarah UKM, kapalkapal yang diproduksi UKM ini, dan proses pembuatan sebuah kapal phinisi. Sehingga diharapakan websites ini dapat memberikan gambaran yang jelas dan singkat mengenai kapal Phinisi khas Sulawesi Selatan.

\section{Target Capaian}

Seperti telah dijabarkan pada bagian sebelumnya, bahwa usaha pengrajin kapal Phinisi di Bulukumba banyak berguguran disebabkan oleh pengelola yang masih tradisional dari para pemilik usaha kerajinan. Sehingga dengan adanya website ini diharapkan, pengrajin kapal Phinisi di Tanah Lemo mampu menggalang kerjasama dengan para pelanggannya secara langsung tampa melalui perantara lagi. Sehingga usaha kerajinan kapal Phinisi di Tanah Lemo mampu berkembang. Dengan demikian, usaha ini akan membuka lapangan kerja bagi para penduduk lokal di daerah tersebut, serta meningkatkan level perekonomian masyarakat di sana.

\section{Implementasi Kegiatan}

Bentuk implementasi dari kegiatan ini, selain melibatkan UD. Bina Pusaka sebagai UKM yang dibina juga bekerjasama dengan tim pengabdian Teknik Sistem Perkapalan Unhas dalam memasarkan produk mereka di dalam dan luar negri via internet. Dalam hal ini pihak Unhas memberikan bantuan berupa

- Bantuan teknis dalam hal pembuatan kapal Phinisi;

- pembuatan websites bisnis; dan

- menjalin kerjasama dengan pihak pembeli kapal Phinisi. 
Dalam hal ini, pembuatan kapal Phinisi berbeda dengan kapal modern. Sehingga mayoritas teknik ketrampilan pembuatan kapal Phinisi dikuasi oleh para pengrajin kapal Phinisi sendiri. Sementara pihak Unhas berperan dalam membuat gambar kapal dan websites.

\section{Hasil dan Diskusi}

UD. Bina Pusaka merupakan UKM yang dirintis oleh masyarakat lokal di Desa Tanah Lemo, dan oleh karenanya memperkerjakan keluarga dan masyarakat sekitarnya. Secara teknis pembuatan kapal Phinisi, UD. Bina Pusaka beserta masyarakat lokal di Tanah Lemo telah berpengalaman selama 31 tahun dan berhasil menjual banyak kapal ke manca negara.

Dengan adanya website bisnis ini, UKM ini mampu berhubungan langsung dengan para pembelinya di manca negara tampa melalui perantara. Sekitar 10 orang yang bekerja pada UD.Bina Pusaka telah menjalani pelatihan mengenai pengoperasian websites ini. Sehingga mereka mampu menjangkau langsung para pembeli kapal phinisi di dalam dan luar negri, Bahkan mereka mampu mempromosikan kapal kapal phinisi yang sementara mereka buat melalui website ini.

Pada website ini juga, mereka memperlihatkan kredibilitas mereka sebagai usahawan phinisi selama 31th, yang telah menjual phinisi hingga manca negara.

Sehinga ketergantungan mereka pada pihak ketiga dalam penjualan kapal phinisi dapat berkurang, sekaligus meningkatkan kesejahteraan mereka melalui usaha ini.

\section{Kesimpulan}

Usaha kerajinan kapal kayu Phinisi merupakan warisan budaya dari leluhur Suku Bugis Makassar dan telah terkenal di manca negara. Pemasaran usaha ini telah bertahun-tahun dan telah berhasil menjual puluhan kapal Phinisi berukuran besar ke luar negri. Namun, karena pengelolan usaha ini yang masih tradisional, maka usaha ini tidak berkembang sebagaimana mestinya.

Oleh karena itu, dengan adanya pemanfaatan websites bisnis diharapkan para pegrajin kayu kapal Phinisi di daerah ini mampu berhubungan langsung dengan para pembeli kapal mereka. Sehingga hasil yang mereka harapkan dari usaha ini mampu maksimal.

\section{Ucapan Terima Kasih}

Ucapan terima kasih kepada Bapak H. Abdullah pemilik dan pimpinan UD. Bina Pusaka atas kerjasamanya memberikan informasi mengenai seluk beluk usaha beliau. Penghargaan setinggitingginya kami berikan juga kepada masyarakat lokal Kelurahan Tanah Beru dalam partisipasinya mendukung kegiatan pengabdian kami. Ucapan terima kasih juga kami berikan pada mahasiswa Teknik Sistem Perkapalan yaitu Yaser, Asia, dan Agung yang ikut membantu pelaksanaan pengabdian di lapangan, serta mahasiswa Teknik Sistem Perkapalan lainnya yang bersedia meluangkan waktunya dalam mengikuti pelatihan pembuatan websites bisnis untuk para pengrajin kapal Phinisi. Penghargaan setinggi-tingginya juga kepada Fakultas Teknik Unhas yang telah memberikan hibah Pengabdian LBE 2019, sehingga pengabdian ini mampu terlaksana dengan sukses.

\section{Daftar Pustaka}

Faithe Wempen, 2011, HTML 5 Step by Step, O’Reilly Media, Inc. 
Karnanda P. 2013. Bisnis Online Pemula. www.BisnisOnlinePemula.com.

Neoelearning. 2014 . Mengenal Bisnis Online lebih Dekat. www.NeoelearningClass.com.

Terry Mc.Navage, 2010, Javascript for Absolute Beginner, Appress.

Tiffany B.Brown, 2015, CSS Master, SidePoint.Pty,Ltd.

Tim Hall and JP.Stacey, 2009, Phyton 3 for Absolute Beginner, Appress. 